\title{
Icufistas en el Río de La Plata: orígenes y devenir de una identidad étnico-política
}

\author{
Nerina Visacovsky
}

CeDoB Pinie Katz - Unsam - Conicet. nerivisa@gmail.com

Title: Icufistas in the Rio de La Plata: origins and becoming of an ethnic-political identity.

Resumen: Este trabajo da cuenta de los orígenes y el devenir del movimiento judeo-progresista en el Río de la Plata entre la Primera Guerra Mundial y el inicio de la Guerra Fría. Frente al avance del fascismo y el antisemitismo, en los años 30, se constituyó internacionalmente el Idisher Cultur Farband (ICUF), liderado por intelectuales judíos comunistas de habla ídish. Vistas en conjunto, las experiencias institucionales reflejan la construcción de una identidad tanto étnica como política. En tanto "judias" se proponían transmitir el patrimonio cultural idishista, pero en tanto "progresistas" postulaban su anhelo de integración a un socialismo universalista. La investigación demostró que esa identidad se modeló en un campo de tensiones entre la pertenencia étnica, los lineamientos del Partido Comunista y la aspiración colectiva de integración nacional, argentina y uruguaya.

Abstract: This work gives an account of the origins and evolution of the progressive Jewish movement in the Rio de la Plata between the First World War and the beginning of the Cold War. Against the advance of fascism and anti-semitism, in the thirties, the Yiddisher Kultur Farband (YKUF) was established internationally. Taken together, institutional experiences reflect the construction of an ethnic and political identity. As "Jews" they intended to transmit the yiddishist cultural heritage, but as "progressive", they postulated their yearning for integration into a universalist socialism. The research work showed that this identity was modeled in a field of tensions between ethnicity, the guidelines of the Communist Party and the collective aspiration for an argentinian and uruguayan national integration.

Recepción: 2 de abril de 2019. Aceptación: 24 de agosto de 2019.

(Archivos, año VIII, $\mathrm{n}^{\circ} 15$, septiembre de 2019, pp. 17-36) 
"Deseamos intensamente existir, pero al mismo tiempo queremos poderosamente dejar de ser..."

H. Leivik ${ }^{1}$

\section{Introducción}

Desde finales del siglo XIX, y sobre todo entre las dos guerras mundiales, arribaron al continente americano grandes contingentes de población judía ashkenazi que, mayoritariamente, provenían de Europa Central y del Este. Si bien traían diferentes oficios, formación educativa o ideas políticas, tenían en común un perfil secular, su idioma idish, ${ }^{2}$ sus tradiciones y una capacidad asociativa que se plasmó en diversas acciones cooperativas, solidarias y politico-culturales. Entre los sectores obreros radicados en el Río de La Plata, hubo quienes militaban o simpatizaban con el anarquismo, el socialismo, el sionismo socialista y el comunismo. Algunos traían consigo su experiencia política europea, y otros la adquirieron en la nueva tierra. En un primer momento, debido a la dificultad idiomática, activaron y divulgaron sus ideas en idish, pero a medida que la integración social iba dando sus frutos y una generación nativa aparecía en escena, esos sectores asumieron como propias las causas de las izquierdas locales. Nos interesa identificar la red de instituciones autodenominadas "judeo-progresistas", adheridas al Ídisher Cultur Farband (ICUF), ${ }^{3}$ que heredaron el trabajo germinal de las secciones idiomáticas de la Komintern, se opusieron al sionismo y, entre las décadas del 30 y 50, construyeron importantes instituciones educativas, deportivas y culturales. La creación del ICUF les brindó un marco ideológico e instaló las máximas que darían contenido al trabajo de sus entidades adheridas: defender la cultura progresista ídish, bregar por la paz y unidad de los pueblos, y luchar contra el fascismo, el racismo y el antisemitismo.

Estas instituciones, que llamaremos "icufistas" o "judeo-progresis-

1. Discurso pronunciado en ídish durante el "Primer Congreso Universal de la Cultura Judia" celebrado en París, 17 a 21 de septiembre de 1937. Traducido en Kornecki (2005).

2. Idioma surgido en el siglo X con la diáspora judía afincada en la zona europea del este alemán. Brevemente, es una lengua que se escribe con caracteres hebreos, pero cuyo vocabulario y fonética fusiona elementos eslavos, semíticos, romances y principalmente germánicos.

3. Federación de Entidades Culturales Judias. Establecida en París (1937) y en Nueva York (1938) con el nombre Yiddisher Kultur Farband (YKUF), y en Buenos Aires (1941) como Idisher Cultur Farband (ICUF). Para aliviar la lectura, usaremos la denominación ICUF en todos los casos. 
tas" indistintamente,${ }^{4}$ fueron multidimensionales desde sus orígenes. Nacieron con la llegada de los inmigrantes y se fortalecieron durante la Segunda Guerra Mundial. Si bien con las masivas migraciones a América existía la posibilidad de que el ídish se perdiera, a partir del genocidio judio, los inmigrantes concibieron con profundo compromiso su conservación y transmisión. Por eso, numerosas entidades idishistas se expandieron hasta inicios de los años 60. La educación y la cultura constituyeron los principales motores de esa experiencia que se asumia tanto étnica como política. La actuación de la Unión Soviética y su Ejército Rojo durante la guerra habian conmovido a gran parte de la izquierda judía que produjo un sincretismo entre su adhesión al comunismo, su lucha contra el antisemitismo y la defensa de su acervo cultural-idiomático.

Entonces, en tanto "judios", los icufistas se proponian transmitir su patrimonio idishista, pero en tanto "progresistas", ligados al Partido Comunista, postulaban su anhelo de construir el socialismo junto a las masas locales. Aquello último requeria consustanciarse con la realidad nacional (argentina y uruguaya) y latinoamericana, lo cual sólo era posible procesando un urgente pasaje al castellano. La hipótesis central que orienta este artículo es que esa identidad se constituyó en un campo de tensiones entre el nacionalismo judio y los lineamientos del Partido Comunista. Y que, además, se materializó en una vasta red institucional cuya agenda internacionalista nació en París, pero fue virando hacia temas nacionales con la aparición de las segundas generaciones. Para decirlo en pocas palabras, los inmigrantes judios progresistas fusionaron procesos de integración al país receptor, militancia o simpatías por el comunismo y (hasta los años 60) la preservación del legado idishista.

En trabajos anteriores, habíamos considerado a la "Asociación Cultural Israelita Zhitlovsky" de Montevideo (de ahora en más, ACIZ) como una de las adheridas al ICUF argentino (Visacovsky, 2015). La investigación posterior develó que aquello no era exactamente así. La cercanía geográfica entre Buenos Aires y Montevideo, hablar el mismo idioma (a diferencia de Brasil) y la condición diez veces menor de la colectividad uruguaya, propiciaban una permanente integración. Sin embargo, desde 1941 a 1968 existió una Federación ICUF de Uruguay que se propuso representar al ACIZ y a otras cuatro entidades montevideanas.

En este artículo describiremos brevemente los procesos de inmigra-

4. Los conceptos "judeo-progresismo" o "icufismo" (por identificarse con la Federación ICUF) son utilizados por los protagonistas indistintamente para manifestar su pertenencia, o la de otros y, al mismo tiempo, diferenciarse del sionismo. Esto ha sido así en Argentina y Uruguay; sin embargo, otras variantes deben considerarse a nivel regional. Por ejemplo, en Chile, el "Centro Progresista Judío Meretz" se asume como entidad sionista de izquierda. 
ción y las tres principales corrientes de la izquierda judía durante los años 20. A continuación, en el contexto de mediados de la década del 30, y al calor de los Frentes Populares, nos detendremos en la creación del ICUF. Finalmente, señalaremos las principales tensiones que los icufistas experimentaron durante la Guerra Fría a la hora de conciliar su condición étnica, las directivas del Partido Comunista y el ánimo colectivo de integración nacional, argentina y uruguaya, respectivamente.

\section{Inmigración judía rioplatense}

Entre las distintas colectividades que arribaron al continente a partir del siglo XIX, los judíos provenientes de Europa Central y del Este se radicaron masivamente en Norteamérica (se calcula que hasta 1924, dos millones atravesaron las puertas de Ellis Island en Nueva York). Entre los países latinoamericanos, Argentina, y en menor grado Brasil, Uruguay y México, fueron los destinos principales (Avni, 1983). Es importante señalar que cuando nos referimos a la "colectividad judia" estamos hablando de grupos con un pasado religioso común, pero muy diferentes improntas idiomáticas y culturales según su lugar de procedencia. ${ }^{5}$ Asimismo, hay que considerar que cuando el inmigrante ingresaba al país, las autoridades le preguntaban por la ciudad o país de origen y no por su religión (Raicher, 2003: 18). Esto ha dificultado construir cálculos y registros exactos de la población judía, en tanto miles de habla ídish entraban en calidad de "rusos", "ucranianos", "lituanos" o "polacos"; y otros, ya integrados a las naciones occidentales, como "franceses" o "alemanes", por ejemplo. Teniendo en cuenta esto se estima que al iniciar la década del 30 en Argentina se registraban 191.000 judios y en 1947, cerca de 273.000 (Jmelnizky y Erdei, 2005:16-24) y que los de habla ídish representaban las cuartas quintas partes del total registrado (Visacovsky, 2015). En el caso uruguayo, se calcula que en 1925 había 6.000 judíos en una población de 1.786 .000 personas y que en 1938

5. Entre mediados de siglo XIX y hasta la segunda posguerra, entre los judios que arribaron a la Argentina y el Uruguay existian significativas diferencias debido a: 1) el idioma y costumbres del país o ciudad de procedencia, 2) el período de arribo y lugar de radicación, 3) la ocupación laboral, 4) la posición económica, 5) el nivel de estudios alcanzados, 6) las ideas políticas, 7) el nivel de secularización. El cruce de estos factores ha producido una gran cantidad de perfiles inmigratorios. En cuanto a su lugar de procedencia, se los puede clasificar en tres conjuntos: a) los ashkenazies, provenientes del Imperio Ruso, que dominaban varios idiomas pero su lengua materna era el ídish; b) los sefaradies, provenientes del Imperio Otomano y zona mediterránea, hablantes del judeo-español o ladino; c) los judíos europeos occidentales de los Imperios Alemán y Austro-Húngaro u otros llegados de Francia, Holanda o Italia, idiomatica y culturalmente identificados con esos paises. 
ascendian a 25.000 en poco más de dos millones de habitantes. ${ }^{6}$ Cerca de un 70\% eran idishistas (Porzecanski, 1990: 24).

En Argentina, a pesar de la existencia de pequeñas colectividades israelitas francesas y alemanas, se considera el desembarco del vapor Wesser, en agosto de 1889, como el hito inicial, con el arribo de 825 inmigrantes judios de Kamenetz-Podolsk, en Ucrania (Avni, 1983). Luego, en 1891, con el vapor Pampa comenzaron los contingentes organizados bajo acuerdos de colonización agraria entre gobiernos provinciales y la Jewish Colonization Association (JCA). Se trataba de familias muy pobres que vivian en aldeas y escapaban de la miseria y los pogroms antisemitas del Imperio Zarista, donde, hasta 1914, 5 millones de judios vivian confinados en la "Zona de Residencia"” (Gilbert, 1978). Más tarde, en el periodo de entreguerras, llegaron judios desde centros urbanos, ${ }^{8}$ sobre todo polacos y lituanos, radicándose masivamente en Buenos Aires.

Tal como otras colectividades de italianos y españoles, los israelitas buscaron oportunidades de progreso y ascenso social a través de la educación, el comercio y la industria (Devoto, 2004). Por eso, a pesar de aquella memorable gesta que Alberto Gerchunoff consagró en Los gauchos judios (1910), promediando la mitad de siglo XX, el 80\% de la colectividad vivía en Rosario, Santa Fe, Córdoba y, enfáticamente, la Capital Federal (Visacovsky, 2015: 36). Los judios porteños se radicaron en los barrios de Once, Villa Crespo y Paternal, donde se dedicaban al comercio, exitosamente movilizado con la venta ambulante y a plazos de los cuénteniks. Los obreros y artesanos se concentraban en los rubros de la confección, sastrería, talleres de costura y otras ramas del vestido como calzado, peletería y gorreria. En Paternal abundaban los carpinteros, ebanistas y lustradores. Con el arribo de los polacos textiles, después de la Primera Guerra, crecieron el tejido y la marroquinería (Bilsky, 1989; Camarero, 2007). En los años 20, las fábricas y pequeños talleres originaron asentamientos periféricos en la zona metropolitana de la Provincia de Buenos Aires: Avellaneda, Lanús, Valentín Alsina y General San Martín, entre los distritos principales.

6. El momento de mayor concentración judía en Uruguay se registró en 1971, con 54.000 judios en una población censada de 2.921.000. Esa cifra se redujo a 23.000 en 1992, pero, aún así, es muy significativo notar que en América Latina, Uruguay es el país con mayor índice de representación de esta colectividad con respecto a su población total (Raicher, 2003: 18-19).

7.Región comprendida en los actuales países de Polonia, Lituania, Ucrania, Rumania y Bielorrusia.

8. Esta nueva etapa de grandes arribos se relaciona también con el cierre de fronteras en Estados Unidos según leyes de cuotas de inmigración establecidas en 1921 y 1924. Esto produjo el desvio de muchos barcos hacia destinos al sur, o directamente, los inmigrantes buscaban los puertos latinoamericanos que permitian la libre entrada. 
En Uruguay, se registraba el ingreso de 93 judíos hasta 1907. Por ese entonces, los gobiernos batllistas habian abierto las puertas a una inmigración no selectiva, confiando en solucionar la grave escasez de población y mano de obra. Aunque varios cruzaban desde Argentina ${ }^{9} \mathrm{o}$ Brasil, después de la Primera Guerra Mundial, Montevideo comenzó a ser recomendado como "el mejor destino americano" porque, a diferencia de Nueva York o Buenos Aires, las autoridades no pedian más que un simple pasaporte (Raicher, 2003: 15-16). Esta apertura continuo al menos hasta mitad de la década del 30, aunque los proyectos de colonización agraria fueron escasos y de corta duración (Porzecanski, 1990). Entonces, radicados en los barrios del Centro, Goes y Unión de Montevideo, los judios se dedicaron al comercio, los oficios artesanales o se emplearon como obreros en la incipiente industria liviana (Raicher, 2003: 20).

\section{Di Linke}

Durante las tres primeras décadas del siglo XX, di linke ("la izquierda", en ídish) compartían las reivindicaciones de la clase obrera local y se habian integrado a sindicatos en las ramas de textiles y madereros. Sin embargo, la dificultad idiomática con el castellano los mantenía socializando en circuitos de su propia colectividad (Bilsky, 1989). En paralelo a las jornadas de trabajo, hombres y mujeres socialistas, anarquistas, sionistas y comunistas, dedicaban su tiempo libre a crear instituciones para "esclarecer a las masas judias y elevarlas culturalmente". Entonces, la edición de publicaciones en ídish, los centros de ayuda y comedores para coterráneos, las bibliotecas, escuelas, teatros y cooperativas, constituian instancias que les permitian activar y militar en su propio idioma; vincularse a proyectos politicos internacionales; desarrollar medios para integrarse y aprender el castellano; ayudar a los recién llegados en su proceso de inserción; y transmitir el legado cultural idishista a las nuevas generaciones. Los linke eran muy parecidos entre sí; venían de los mismos pueblos, hablaban en ídish, eran laicos y marxistas. Todos apostaban a "progresar" en la nueva tierra americana, pero la divergencia en sus proyectos políticos les impedía

9. Durante los gobiernos de José Batlle y Ordóñez (1903-1907 y 1911-1914) y Claudio Williman (1907-1911) se permitió la entrada a inmigrantes socialistas y anarquistas que Argentina expulsaba de acuerdo con su Ley de Residencia 4.144 de 1902. Asimismo, después de 1917 se permitió el ingreso a inmigrantes provenientes de Rusia y, desde 1928, pudieron efectuar el trámite de nacionalización uruguaya (Raicher, 2003: 9). 
forjar instituciones conjuntas (caso argentino), o sostenerlas en el largo plazo (caso uruguayo).

Las lineas de izquierda surgidas en Europa y consolidadas en esta región durante la primera mitad del siglo XX tuvieron su expresión en la prensa y las redes institucionales. En primer lugar, los "bundistas", del Partido Obrero Judio Bund (Unión), ${ }^{10}$ creado en Vilna en 1897, fundaron en 1908 el grupo Avangard (La Vanguardia). Defendieron el ídish y se opusieron tanto al territorialismo sionista como al unipartidismo leninista. En el Río de La Plata, su ideario coincidió con los Partidos Socialistas, pero, hasta la Segunda Guerra Mundial, respondian a las directivas del Bund de Polonia (Laubstein, 1997). En los años 30 abrieron escuelas idishistas complementarias en Buenos Aires, replicando el modelo polaco. En Montevideo, al ser muy pocos, desarrollaron escuelas junto a los comunistas. En segundo lugar, los "Linke Poale Sionistas", sector de izquierda del movimiento Poale Sion (Trabajadores de Sion), que siguiendo al ucraniano Dov Ber Bórojov planteaban la necesidad de reunir al pueblo judio en un mismo territorio como paso previo a la revolución socialista. Con posiciones radicalizadas o reformistas, fueron judíos laicos, pero nacionalistas y, más tarde, serian activos promotores de la migración al Estado de Israel y los movimientos kibbutzianos. En los años 20, crearon escuelas obreras Bórojov, laicas y contestatarias, que fueron clausuradas por "comunistas" a inicios de los años 30. Empero, al final de esa década renacieron con el nombre "Sholem Aleijem" y adoptaron el modelo pedagógico de sus pares en Polonia. Después de la Segunda Guerra se integraron a otros movimientos sionistas juveniles de base marxista como Hashomer Hatzair (Joven Guardia) o "Mordejai Anilevich". ${ }^{11}$ La tercera línea, la marxista-leninista (base del judeo-progresismo) surgió cuando el sector internacionalista del Bund se fraccionó y un significativo grupo adhirió a la Komintern. Así, nació en 1921 la Ídishe Sektzie des Komunistishes Partei, conocida como la Idsektzie en el Río de la Plata (Yevsektzia para los rusos). Es preciso destacar que judios anarquistas que habian participado de las luchas sindicales a principio de siglo ${ }^{12}$ también se sumaron a la Idsektzie. Las

10. Forma abreviada de Algemeyner Yidisher Árbeter Bund fun Rusland, Poyln un Lite: Unión General de los Trabajadores Judios de Rusia, Polonia y Lituania.

11. Después de la creación del Estado de Israel, los linkepoalesionistas se integraron a los partidos de la izquierda israelí que orientaron la coalición liderada por David Ben Gurión. Entidades como las escuelas Scholem Aleijem Central, la emblemática Sociedad Hebraica y el diario Nueva Sion fueron en Buenos Aires los principales referentes de la izquierda sionista (Toker y Weinstein, 1999). Para el caso uruguayo, ver el trabajo de Graciela y Víctor Ben Dror (2016).

12. En Buenos Aires, varios acontecimientos indican el protagonismo judío en el anarquismo: la página en ídish que desde el año 1908 salía en el diario La Protesta 
influencias del pasado anarquista y bundista en el sector comunista son muy evidentes, tanto en la prensa como en los contenidos de enseñanza de sus escuelas complementarias idishistas (árbeter shuln) de los años 20 (Visacovsky, 2015: 69).

Entre las primeras iniciativas de la izquierda judía sobresale la actuación del "Centro Literario y Biblioteca Israelita Max Nordau" de la ciudad de La Plata, fundado el 20 de junio de 1912. Allí se organizó la "Primera Convención Israelita de Cultura en la República Argentina", en noviembre de 1915. Inspirados en las bases del famoso congreso idishista de Chernovitz en 1908, se reunieron delegados representando a catorce asociaciones de Santiago del Estero, Tucumán, La Pampa y Santa Fe, entre otras localidades. Fue un encuentro federal, pero también plural, porque habia sectores anarquistas y también religiosos. Por los socialistas de Avangard coordinaban Pinie Wald y el obrero gráfico Máximo Rozen (Sak, 2000: 107), quien más tarde sería el máximo líder de la Idsektzie (Camarero, 2007: 301). Alli acordaron defender la cultura idishista y desarrollar acciones para promover la integración al país. Esto implicaba crear escuelas para niños y bibliotecas populares en ídish, pero también dictar cursos nocturnos de castellano, historia política, economía y estudio de la Constitución Nacional para adultos. ${ }^{13}$ Posteriormente, estas acciones entroncaron con el impulso de la Komintern y su Idsektzie en los años 20.

En Buenos Aires, en 1929, la federación escolar Arbeter Shul Organizatie, declaraba el éxito creciente de sus árbeter shuln, ocho "estrellas rojas" brillando en los barrios de Once, Paternal, Villa Crespo, Villa Devoto, Avellaneda y Valentín Alsina. Siempre complementarios a la escuela estatal obligatoria, esos shules obreros constituian parte de un entorno más amplio de bibliotecas y centros socio-culturales que funcionaban en casas particulares o habitaciones alquiladas. Asimismo, también allí se realizaban las reuniones del proyecto de colonización en Birobidyán, conocido como PRO-COR, ${ }^{14}$ la comisión ejecutiva de la Idsektzie, o la actividad de prensa ídish, entre otras.

(Díaz, 2016); el atentado al jefe de policía Ramón Falcón, responsabilidad del judío ucraniano Simón Radowitzky en 1909; las fatídicas jornadas de la Semana Trágica, en enero 1919, cuando además de la represión obrera generalizada, tuvo lugar un violento pogrom antisemita perpetrado por fuerzas policiales y civiles (Katz, 1980; Wald, 1998). El "maximalismo ruso" que agitaba a la clase trabajadora era asociado a la presencia judia y anarquista en la región. En Montevideo, los anarquistas de habla ídish tuvieron gran actuación en las huelgas obreras (Diaz, 2019) y fueron precursorores, en 1925, del Centro Morris Winchevsky, antecesor de la institución ACIZ.

13. Comisión Directiva, Max Nordau. Publicación 80 Aniversario, La Plata, 1992, pp. $2-4$.

14. La "Sociedad de Ayuda a los Colonos Israelitas en la Rusia Soviética", conocida 
En Argentina, a partir del golpe cívico-militar del 6 de septiembre de 1930, bajo los efectos de la crisis de Wall Street y los ecos del fascismo europeo desafiando a las democracias liberales, avanzaron los sectores nacionalistas más conservadores, concentrados en las Fuerzas Armadas, la Iglesia Católica y las elites tradicionalistas. Esta configuración perduró durante el mandato de Agustín P. Justo iniciado en 1932 y encontró su ápice con un nuevo golpe de estado en 1943. Ese período se caracterizó por la represión policial al comunismo y su proscripción en determinadas provincias, se reprimieron las organizaciones obreras en general y se clausuraron tanto las escuelas idishistas de la Idsektzie, como las Bórojov del Linke Poale Sion, entre decenas de organizaciones obreras. Pero, a pesar de las persecuciones y la ola represiva, la adhesión al comunismo crecía en la "calle judia" por varios motivos. En primer lugar, a diferencia del Partido Socialista, la Komintern permitia a sus militantes utilizar el idioma ídish, y los reconocía parte de un movimiento internacionalista de masas. En segundo término, las noticias acerca de los derechos igualitarios para las minorias en la URSS y el crecimiento del proyecto Birobidyán se vivian como reparaciones históricas, después de tantos padecimientos sufridos en la "Zona de Residencia". Así es que no sólo crecían las simpatías por el comunismo entre los grupos de izquierda idishista, sino que, además, la Idsektzie era la más numerosa entre las secciones idiomáticas que integraban el Partido Comunista argentino (Camarero, 2007: 297-311) y fue la única que logró montar redes escolares marxistas para niños y jóvenes.

En Montevideo, durante los años 20, el sector marxista-leninista constituyó un núcleo mayor y más activo que el de bundistas y linkepoalesionistas (Schonebohm 1991: 59). Sin embargo, al ser una colectividad más pequeña, al comienzo actuaban juntos en las movilizaciones y organizaciones. Algunos indicadores, no obstante, permiten observar el liderazgo de la Idsektzie en dos emblemáticos barrios obreros: Centro y Goes. Los primeros inmigrantes judios rusos habian fundado un Idish Kultur Center y una Biblioteca Sholem Aleijem entre 1917 y 1918. Esas dos iniciativas se unificaron en 1925 y adoptaron el nombre de Centro Cultural "Morris Winchevsky" (llamado "el Morris"). Desde alli se incentivaba a los obreros idishistas a participar de la actividad

por su sigla PRO-COR, trabajaba ligada a la Idsektzie. Además de las campañas para recaudar dinero, y aunque los permisos soviéticos eran limitados, algunas familias se postularon para viajar a Birobidyán en 1929. En 1941, la República Judía soviética contaba con 128 escuelas primarias que enseñaban ruso e ídish, varios diarios y teatros en ídish, y 27 granjas colectivas israelitas. En 1959, según el censo local, se registraban 14.200 judíos viviendo allí, de los cuales un $40 \%$ hablaba ídish. En 1976 se calculaban en menos de 12 mil, un $15 \%$ de la población que se reconocía judía en la URSS (Gilbert, 1978). 
sindical de sastres, carpinteros, zapateros, trabajadores del cuero y textiles (Porzecanski, 1990: 88) y también se organizó un comedor popular. Entre 1925 y 1934, el Morris ocupó locales que compartía con el Partido Comunista del Uruguay (Schonebohm, 1991: 67). La actitud internacionalista y antirreligiosa se hacía evidente en proclamas como la de 1926, donde se invitaba a los obreros judíos a integrar un "Comité Unificado anti-Yom Kipur" junto con "la Sección Judía del Partido Comunista" y boicoteaban la concurrencia de los niños a las escuelas sionistas. En 1931, informaban contar con 284 socios aportantes y convocaban a colaborar con el "Comité Pro-Refugiados Políticos de Socorro Rojo Internacional" (MA-POR) y la campaña financiera "Un tractor para Birobidyán” del PRO-COR. En 1929, el Morris ayudó a la creación del Club Obrero Avangard del barrio de Goes y entre 1931 y 1932 se abrieron escuelas obreras (árbeter shuln) en los dos barrios. En 1936 tenían una matrícula de 200 alumnos y un programa escolar que difundia las gestas obreras y rechazaba la historia judeo-religiosa por su condición "reaccionaria". Las dos fechas celebradas con devoción eran el $1^{\circ}$ de Mayo, día del trabajador, y el 7 de noviembre, inicio de la Revolución bolchevique. ${ }^{15}$

Paralelamente, la colectividad israelita uruguaya desarrolló otras organizaciones de ayuda a los inmigrantes, donde también actuaban los simpatizantes comunistas (Leibner, 2011: 185). Especialmente reivindicada por el judeo-progresismo fue la fundación de la "Primera Cooperativa Judia de Ayuda Mutua en Villa Muñoz" (Goes) en 1925. En sus orígenes nació en una sinagoga, pero más tarde sionistas y progresistas que la integraban se disputaron su control. Finalmente, los segundos ganaron su dirección y en 1938 la convirtieron en el Banco Israelita Uruguayo. Con su ayuda financiaron escuelas, bibliotecas, un proyecto agrario e incluso comprarian el legendario Café Vaccaro de Goes para actividades culturales. Asimismo, en 1929 se creó un Fondo de Previsión (en 1941, Mutual Israelita del Uruguay, MIDU) para brindar asistencia médica y subsidios a 700 socios en caso de enfermedad, fallecimiento o algún tipo de urgencia familiar. La MIDU, además, tramitó la compra y construcción de un cementerio judío laico, una inédita experiencia en Sudamérica, donde los idishistas podían ser enterrados sin rituales religiosos y respetando su adscripción política marxista. Más adelante, hacia 1962, la MIDU construiria su propio servicio y sanatorio de salud. En definitiva, la cooperativa de crédito (luego Banco) y el fondo de previsión (luego MIDU) con sus ramificaciones, surgieron en la década del 20, los judíos comunistas centralizaron su conducción en los años de la Segunda Guerra y lograron una notable expansión de allí en más. 
Pero volviendo al escenario de 1933, mientras el fascismo avanzaba en Europa, en Uruguay iniciaba la dictadura de Gabriel Terra y se creaba un "Frente contra el Antisemitismo en Alemania" encabezado por el Centro Morris Winchevsky e integrado por las instituciones uruguayas antes mencionadas. En Argentina, comenzaba a funcionar la "Organización Popular contra el Fascismo y el Antisemitismo" ${ }^{16}$ y varios intelectuales y activistas se habian sumado al Socorro Rojo Internacional para ayudar a las víctimas de la represión obrera iniciada por José Félix Uriburu en 1930, continuada por Justo en 1932 y con especiales brotes antisemitas hacia 1936 y 1937. Las resonancias de la Guerra Civil Española reeditaron el mito judeo-bolchevique y el gobierno prohibió la prensa y el uso del ídish en actos públicos, calificando al idioma como "código secreto" para transmitir "ideas disolventes". El golpe militar de 1943 agudizó la represión obrera y potenció la xenofobia y el nacionalismo autoritario pro-fascista en el gobierno. Durante ese año, entre otras medidas, se suspendió la actividad de los partidos políticos, se clausuraron todos los diarios "progresistas" y se decretó, a nivel nacional, la enseñanza religiosa en la escuela estatal. En Uruguay no faltaron las expresiones antisemitas durante esa época (Feldman, 2001), pero no hubo políticas estatales de censura y persecución. Durante los años de la Segunda Guerra, la neutralidad uruguaya tenía un sesgo democrático e identificado con los países aliados (Raicher, 2003: 100) y el catolicismo no tenía los rasgos integristas de la Iglesia argentina. En definitiva, en ambos países, en los años de la Segunda Guerra, los sectores idishistas de todas las tendencias de izquierda fueron parte activa del frente antifascista y se sumaron a organizaciones más amplias, con frecuencia, lideradas por comunistas.

\section{La Federación ICUF: del frentepopulismo a la Guerra Fría}

En su VII y último congreso, realizado en Moscú entre el 25 de julio y el 20 de agosto de 1935, la Komintern llamó a constituir Frentes Populares para combatir al fascismo (Crespo, 2010). En ese marco, las secciones idiomáticas de habla ídish en cada país, buscaron construir alianzas con los socialistas del Bund, el Linke Poale Sion y la "burguesia judia progresista". Esta misión era particularmente dificil después de las agresiones durante el Tercer Periodo (1928-1935), donde la linea de "clase contra clase" había enfrentado a los dirigentes de aquellas

16. Liderada por Pinie Katz y la colaboración de Simón Gordon en Buenos Aires y Mina Fridman Ruetter, desde Rosario. Esa organización, publicaba las revistas Af der waj, en ídish, y En guardia, en castellano. En 1935 editaron en ídish dos libros: El plan de Hitler y El libro pardo del fascismo. 
corrientes. Sin embargo, frente al avance del antisemitismo en Europa, la movilización frentepopulista liderada por los comunistas encontró eco en "la calle judia". Así fue que, desde 1936, los principales intelectuales idishistas europeos y americanos comenzaron a organizar el Primer Congreso de la Cultura Judía, que se realizó en París, entre el 17 y el 21 de septiembre de 1937. Mientras el mundo se polarizaba frente al conflicto en España, representantes de 23 países, reunidos en aquel Congreso, crearon la Federación ICUF. El referente y miembro de la Idsektzie en esos años, Pinie Katz, actuó como delegado en París, representando a 5 organizaciones uruguayas y 22 argentinas. A su retorno, él y otros activistas rioplatenses trabajaron por difundir el icufismo entre las organizaciones existentes y crear otras nuevas. ${ }^{17}$ En el Manifiesto del ICUF se acordó luchar contra el fascismo y defender la cultura y el idioma ídish. Para ello había que crear escuelas, teatros, literatura y fomentar las artes "llamando a la unidad de las fuerzas progresistas". $\mathrm{El}$ escenario era complejo, porque si bien había acuerdo en la necesidad de unir a los linke, el enfrentamiento ideológico existente, que más tarde se potenció por el pacto germano-soviético, ${ }^{18}$ dificultaba el logro de acciones conjuntas. Por otra parte, el ICUF se había estructurado con una dirección en París, dos secretarias en Nueva York y Varsovia y secciones nacionales en el resto de los países. Sin embargo, la guerra lo alteró todo y, en el marco de esa tragedia y a pesar de que Nueva York centralizó las tareas, las secciones sudamericanas ganaron autonomía. El 11 abril de 1941 tuvo lugar un Congreso de la Cultura Judía en Buenos Aires, donde, replicando el evento de 1937, se constituyó el Idisher Cultur Farband en Argentina. Participaron 57 instituciones representando a 8.900 asociados de Argentina, Uruguay, Brasil y Chile. Los uruguayos también crearon su propia Sede ICUF en Montevideo, para coordinar el trabajo de las organizaciones afines. ${ }^{19}$

17.El listado de instituciones adheridas puede verse en los cuadros anexos del presente dossier.

18. En cuanto a eso, en líneas generales, mientras los comunistas entendieron que se trataba de una estrategia de Stalin para salvar a la Unión Soviética de las potencias capitalistas, que esperaban verla desplomarse a manos de los nazis, los bundistas, liderados por Polonia, con la firma de este pacto habían llegado al punto máximo de aversión hacia los bolcheviques. Sin embargo, la gran convocatoria que generó el congreso del ICUF en Buenos Aires (abril 1941), acontecida antes de la ruptura de aquel pacto (junio 1941), muestra que, si bien ese acuerdo profundizó diferencias existentes, no fue la causa que determinó el éxito (o eventual fracaso) del movimiento icufista en la calle judia.

19. La Federación ICUF de Uruguay se disolvió en 1968 cuando las entidades se fusionaron y ACIZ concentró la actividad de los progresistas (Schonebohm, 1991: 65). Sin adhesión formal, Montevideo funcionó integrada a la red argentina. Desde los 
Poco tiempo después, en el campo internacional, la conformación de los Aliados, la resistencia del Ejército Rojo en el frente oriental y la Batalla de Stalingrado entre junio de 1942 y 1943, produjeron nuevas valoraciones internacionales con respecto a la URSS. Al finalizar la guerra, en 1945, los soviéticos habian perdido " 27 millones" de hombres ${ }^{20}$ pero se coronaban "los salvadores de la humanidad", y así los verian de allí en más los icufistas. Entonces, bajo el signo de los Frentes Populares, durante las décadas del 40 y 50, gran parte de la "burguesia" y el "obrerismo" judío simpatizaron con el comunismo y los icufistas ganaron popularidad llegando incluso a obtener un 35\% de representación en la Asociación Mutual Israelita Argentina (AMIA) ${ }^{21}$ y subsidios para cinco de sus escuelas. Sin embargo, desde la creación del Estado de Israel en 1948, las organizaciones sionistas fueron paulatinamente hegemonizando el campo comunitario. El centralismo de Israel como nuevo horizonte nacional para los judíos "de la diáspora", la adopción y enseñanza del hebreo moderno y la convocatoria enfática a migrar al nuevo Estado ("hacer la alia") se volvieron los objetivos de la mayoría de las instituciones. Los icufistas no acordaban con aquello ni con la vía belicista para solucionar los conflictos en Medio Oriente, pero apoyaron la creación de Israel y realizaron importantes colectas (Campaña Popular) para financiar la construcción de escuelas, casas y hospitales alli. Mientras la Unión Soviética había colaborado con el surgimiento del

años 50 fueron particularmente activos los encuentros entre organizaciones juveniles y femeninas. La Federación de Instituciones Juveniles Israelitas Argentinas (FIJIA) y Federación de Instituciones Juveniles de Judíos Uruguayos (FIJJU) organizaron encuentros deportivos y culturales, que más adelante se llamarian "Icufiadas". La Organización Femenina del ICUF (OFI), fundada en 1947 sobre la base de los círculos de lectura (leien craizn), invitó a las comisiones femeninas uruguayas a participar en su Primer Congreso de la Mujer Judía, celebrado en Buenos Aires en 1957 y en su revista Di Ídishe Froi (La Mujer Judia). Entre las segundas y terceras generaciones fueron frecuentes los encuentros de Kinder-clubes y otras instancias pedagógicas.

20. Eric Hobsbawm (2007: 51) afirmaba que las bajas en los territorios soviéticos, como todas las cifras exactas de la segunda guerra mundial son meras especulaciones. En diversas ocasiones, fuentes oficiales han llegado a calcular 7, 11, 20 o 30 millones. Elegimos la cifra de 27 millones porque es la que utilizaban los icufistas en sus discursos y publicaciones.

21. En las primeras elecciones de 1949 , con un padrón de 40.000 socios, votaron 10.000 y se presentaron tres listas; los sionistas sacaron 5.085 votos, los independientes 1.236 y los progresistas 3.474. En las de 1951, con dos listas y 11.901 votantes, el sionismo sacó 7.857 sufragios y el progresismo 4.046 (AMIA, 1996: 115123). Cabe mencionar que, dado que la colectividad judía argentina se estimaba en 300.000 personas, los icufistas sostenían, con evidentes razones, que los resultados de las elecciones de AMIA no eran representativos del pensamiento político judío en Argentina. 
estado israelí, las aguas estaban más calmas, pero en cuanto el gobierno de David Ben Gurión se alineó con Estados Unidos, las tensiones entre sionistas y progresistas renacieron.

Por otra parte, durante la década del 40 , la vida judía en la URSS contaba con gran reputación. Las obras de los escritores idishistas a favor del socialismo y la Revolución de Octubre, el desarrollo de Birobidyán, las causas antifascistas y la integración de los judíos a las más altas esferas de la sociedad, eran tópicos exhibidos por los icufistas para señalar los caminos del "progreso humano" y "el hombre nuevo". Sin embargo, el armonioso idilio con el estalinismo de posguerra comenzó a entrar en crisis a medida que llegaban las noticias de las purgas. Para empezar, se supo del extraño accidente automovilístico del director teatral ídish Salomón Mijoels en Minsk, en 1948. A pesar de haber sido enterrado con todos los honores, pronto circuló la versión de que se trataba de un asesinato a las órdenes de Stalin. Posteriormente, se supo de los procesos de Praga, donde Rudolf Slánský y otros diez dirigentes judios checoslovacos, por una parte, y trece escritores judíos del Comité Antifascista, por otra, habian sido juzgados injustamente y asesinados en agosto de 1952. A eso le siguió el supuesto "complot de los médicos judíos" de 1953, denunciados por Stalin antes de morir. Aquellos hechos fueron tomados como argumentos centrales de la campaña internacional contra el "antisemitismo soviético", lanzada por el sionismo entre 1952 y 1953.

En el marco de aquella confrontación, el ICUF fue expulsado de la AMIA. Los progresistas, sin embargo, sostenían que la condena a la URSS era una pantalla, porque la verdadera finalidad de los "reaccionarios sionistas" era quitarles niños de sus escuelas que, para entonces contaban con 1500 alumnos y un reconocido prestigio pedagógico. Aquella excomunión, o "jerem", se originó con una proclama de la Delegación de Asociaciones Israelitas Argentinas (DAIA) convocando a repudiar a la URSS por los juicios antisemitas de Praga. En la asamblea del 18 de diciembre de 1952, los dirigentes del ICUF, Ioel Linkovsky y Mijl Raizman, rechazaron firmar ese documento, mientras DAIA y AMIA informaron a sus asociados que "no se debía enviar niños judios a escuelas identificadas con la política soviética". Varios indicadores permiten concluir que existia un profundo desacuerdo preexistente, y que los sionistas estaban esperando un conflicto internacional como el de 1952 para alejar a los progresistas de las organizaciones centrales y las posiciones de poder (Zadoff, 1994: 412-414). Así, al iniciar 1953, los icufistas perdieron sus cargos en la Comisión Directiva y los subsidios para sus escuelas.

En el marco de la guerra fría, la lógica de "amigos y enemigos" colocaba a los judíos-progresista en un complejo campo de tensiones. El sionismo los acusaba de "sectarios comunistas" y el Partido Comu- 
nista argentino, en ocasiones, de "sectarios judíos". Desde el triunfo del peronismo en Argentina, el PC, en su XI Congreso de 1946, había comenzado a cuestionar a sus militantes o simpatizantes judios que no lograban integrarse con las masas trabajadoras. Sobre todo, durante el peronismo, la defensa de la cultura idishista era interpretada por la dirigencia del PC como un "sectarismo europeo". Retrospectivamente, varios activistas interpretaron que esa conjunción entre la demanda forzada del partido para que se "acriollasen", y la excomunión de las organizaciones judias centrales, ganadas por el sionismo, empobrecieron al movimiento icufista. Sin embargo, mientras algunos abandonaron el ICUF por su incondicional alineamiento con el PC, otros conservaron su idealismo pro-soviético anudado a la Segunda Guerra Mundial y concentraron en la figura del "traidor Beria" toda la responsabilidad por las purgas estalinistas. La prensa, a cargo de la Comisión Israelita del PC-ICUF, logró instalar banderas muy efectivas para evitar quiebres en las instituciones; la causa de Julius y Ethel Rosenberg, acusados de espionaje y ejecutados en Estados Unidos en 1953, fue presentada como el máximo símbolo del antisemitismo capitalista; mientras la lucha por la paz en Medio Oriente reafirmaba el reconocimiento del Estado de Israel, pero cuestionaba su rol como base del "imperialismo yanqui" y opresor del pueblo palestino. Poco tiempo después, a raíz de las declaraciones "secretas" de Nikita Jruschov en 1956, durante el XX Congreso del PCUS, tanto en Argentina como en Uruguay, algunos simpatizantes o militantes desilusionados del estalinismo se alejaron definitivamente del PC (Leibner, 2011: 186). Sin embargo, para varios otros, los procesos conocidos como el "deshielo" y "la vuelta a Lenin" renovaron la creencia de que existía alli "un socialismo genuino", que solo necesitaba ser reencauzado.

En sintesis, la colectividad judeo-argentina institucionalizada tomaría en la segunda mitad de los años 50 la forma del escenario internacional, ubicándose a cada lado de "la cortina de hierro". A medida que la guerra fría se intensificaba, los circuitos institucionales se volvian más irreconciliables; sionistas, de izquierda a derecha, por un lado, y progresistas, por el otro. Sin embargo, el impulso expansivo de la red icufista, con su fuerte impronta cultural y educativa seguía permeando en las segundas generaciones. Su nueva condición de sectores medios se reflejaba en el crecimiento de edificios y mayor afluencia de niños y adolescentes a las actividades educativas no formales: kinder clubes, jardines de infantes y colonias. Esto sucedia porque la propuesta era de excelencia y porque, en buena parte, las redes de socialización resistian las disidencias partidarias. 


\section{La matriz icufista y sus instituciones}

Tal como se había planteado en los Congresos del ICUF, que siguieron realizándose cada dos, tres o cuatro años, la cultura y la educación constituían los grandes pilares del movimiento. En Argentina, en 1946, la red contaba con 9.000 asociados y en 1955, con 20.000 en todo el país (Visacovsky, 2015). No contamos con cifras exactas para Uruguay, pero el semanario Unzer Fraint, publicado sin interrupciones a lo largo de cuarenta años en Montevideo (1935-1976) y leído asiduamente por el público icufista, tenía un tiraje de 5.000 ejemplares, mientras las contribuciones para el "Palacio ACIZ" inaugurado en 1950 provinieron de 1.200 aportantes (Schonebohm, 1991: 67). Aquella expansión, además, era posible porque buena parte de los obreros idishistas habian progresado económicamente y podian aportar tiempo o dinero (o ambas cosas) al desarrollo institucional. En este punto, también los emprendimientos cooperativos cumplieron un rol fundamental. En Montevideo, el Banco Israelita del Uruguay; en Argentina, una serie de cajas de crédito propias (más tarde, independizadas y convertidas en Banco Credicoop).

Mientras varias instituciones funcionaban en inmuebles alquilados, otras habian logrado comprar y arreglar edificios. Un ejemplo emblemático en Argentina fue el Palacio Cultural y Deportivo I.L. Peretz en la zona textil de Villa Lynch. La obra se realizó en etapas: comenzó en 1943 con aulas y una cancha de básquet, en 1947 inauguraba un teatro para 400 personas, la biblioteca, salas para el jardín de infantes, y terminaría en los años 60 inaugurando un edificio de cinco pisos con pileta olímpica. Otro ejemplo fue el Palacio I.L. Peretz de Lanús, otro distrito fabril, donde en 1956 se logró construir un edificio de cuatro pisos para la escuela y un gran teatro en zona céntrica. En 1950 se logró comprar el predio de la colonia Zumerland en la localidad de Mercedes y en ese año también se inauguró el monumental Teatro IFT en el barrio de Once, símbolo y referente del arte dramático judeo-progresista y el teatro independiente, cuyo impacto cultural trascendió a otras provincias y países limitrofes. En Uruguay, en 1950, se inauguraba el "Palacio ACIZ", con un edificio de seis pisos para la escuela, varios patios, biblioteca y un teatro para 500 personas. Iniciativas como estas se multiplicaban en otras provincias y, si bien la atmósfera ideológica de izquierda caracterizaba a los "palacios progresistas", éstos se brindaban abiertos a todo público. A nadie se preguntaba allí por su pertenencia étnica o su inclinación política, eran instituciones judeo-progresistas, pero también eran instituciones "de y para el barrio".

Debido a su potencial formativo, las instancias educativas constituyeron la actividad más preciada para la dirigencia. En Argentina, los quince shules que existían en los años 50 funcionaron como escuelas 
idiomáticas no formales, complementarias a la estatal obligatoria. Algunos tuvieron jardín de infantes (kinder-gortn) y dos de ellos (Zhitlovsky de Villa del Parque y Peretz de Villa Lynch), un secundario de tres años con orientación pedagógica, denominado Mitl-shul (Visacovsky, 2015: 168). Asimismo, las generaciones jóvenes, en línea con las teorias pedagógicas que circulaban en el entorno comunista (Carli, 2005; Visacovsky, 2017) focalizaron su interés en kinder clubes, y otras actividades recreativas entre las que se destacó la colonia Zumerland.

En cuanto al trabajo cultural, entre 1946 y 1980 el ICUF Buenos Aires publicó cerca de 82 títulos con su propia editorial. Hasta 1958, abundaron las traducciones de clásicos del castellano al ídish, como la laboriosa versión de Don Quijote de Miguel Cervantes Saavedra, que realizara Pinie Katz. Posteriormente, desde 1958, las traducciones se hicieron a la inversa, las obras más famosas de la literatura ídish, como los cuentos de Scholem Aleijem, fueron publicadas al español. Así también más de 35 títulos de autores soviéticos se tradujeron del ruso al ídish bajo el sello Heimland (Patria). En cuanto a la prensa, si bien todo el arco idishista desarrolló un trabajo destacado, la línea comunista fue especialmente prolífica (Dujovne, 2008: 123). En 1940 salió la revista $I C U F$, en los años 50 apareció mensualmente Aporte, redactada por la juventud de FIJIA; y entre los 50 y 60 la Organización Femenina del ICUF editó Di ídishe froi. Desde el Consejo de Escuelas del ICUF (Shul Rat) se publicó Kindervelt y cuentos en ídish para niños. Así también, en todas las épocas salieron semanarios o revistas mensuales ideológicamente afines, editadas por miembros de la Comisión Israelita del Partido Comunista (antes Idsektzie). Hasta 1940, fueron Avangard, Vida Obrera, Di Presse, Der Roiter Shtern, Naie Erd, In Gang, Naivelt, y Af der Vaj entre las principales. Durante la Segunda Guerra, se publicaron Di Voj ( $L a$ Semana) y Folkshtime (La Voz del Pueblo) y en la posguerra salieron Der Veg (La senda) y luego Haint (Hoy). Bajo la dirección ideológica de Rubén Sinay, en 1951 comenzó Tribuna (bilingüe) y desde 1968 y hasta finales de los años 80, la revista Tiempo en castellano. Renovación en los 60 y Unzer Lebn (Nuestra Vida), con la dirección de Tzalel Blitz, completan el mapa de las más leídas por el icufismo. ${ }^{22}$ En los años 20, en Montevideo, cuando aún no había imprentas en ídish, las publicaciones se mandaban a editar a Buenos Aires. Esto cambió en la década del 30, cuando la Idsektzie uruguaya sacó el primer número de Tzum Oktiaber (Hacia Octubre), un semanario en sintonía con Der Roiter Shtern. Ambos fueron los antecedentes del emblemático semanario Unzer Fraint, publicado

22. Comité Especial, 50 Años de la prensa judía progresista en la Argentina 19231973, Buenos Aires, 1973 (la publicación contiene errores que fueron enmendados por la autora de acuerdo a otra documentación). 
entre 1935 y 1976 bajo la dirección de Abraham Jeruzalimsky y Moishe Richter en su primera etapa y el periodista Mario Chiz en la segunda.

En definitiva, el movimiento institucional y la prensa judeo-progresista se expandieron por etapas hasta los años 60 y 70 . Para entonces, comenzó un proceso de recambio generacional; los jóvenes celebraban la revolución cubana, defendian la educación laica, el reformismo universitario, y manifestaban intereses que estaban más allá de la institución idishista. Paralelamente, las crisis internacionales del comunismo y las transformaciones sociales y económicas del período obligaron a los icufistas a un urgente aggiornamento, y las actividades en idish fueron las grandes perdedoras. Empero, el pleno pasaje al castellano permitió incorporar a un público más vasto, no exclusivamente judío, y dar sentido al lema internacionalista que orientó su devenir: construir instituciones cuyo transitar fuera "desde lo particular hacia lo universal".

\section{Reflexiones finales}

En Buenos Aires y Montevideo, durante los años 20, las escuelas y centros culturales idishistas habian sido "obreros" marxistas-leninistas $y$, aunque restringidas sus libertades en los años 30, pudieron en los 40, en el marco frentepopulista, renacer como instituciones judias "laicas" y comenzar un camino ascendente en cantidad de público, recursos y organización. A finales de la década del 50, los judíos progresistas ya formaban parte de los sectores medios rioplatenses, y acompañaban el desarrollo de una generación de hijos nativos que ingresaba a la universidad. La década del 60 se abrió con vertiginosas transformaciones juveniles (Manzano, 2017): la revolución sexual, el nuevo rol de la mujer en el mercado de trabajo, la música rock, las modas y el consumo interpelaban al viejo shule idishista de posguerra. Asimismo, la adopción del hebreo como idioma oficial israelí, en detrimento del ídish, había traído consecuencias negativas para toda actividad en esa lengua, en el país y el mundo. Finalmente, la Guerra Fría, las crisis del comunismo estalinista a nivel internacional y el anquilosado Partido Comunista habían producido el desplazamiento de la juventud intelectualizada hacia otras fuerzas politicas de izquierda (Altamirano, 2001). Tanto en Buenos Aires como en Montevideo, la juventud "progresista" se inclinó a participar de otros espacios sociales y políticos dónde "lo judio" dejaba de ser una marca diferencial.

La anhelada integración social que traían los inmigrantes daba por fin sus frutos, pero al mismo tiempo se perdia la cultura idishista y se debilitaban las características étnicas de las instituciones. Los icufistas discutieron estos problemas en su IX Congreso de 1968. Una posibilidad de enfrentar el desinterés por los shules era convertirlos en escuelas 
modernas, tal como estaban construyendo los sionistas, subsidiados por AMIA y organizaciones israelies. Sin embargo, crear escuelas que "compitieran" con la estatal iba en contra del principio universalista e igualitario del progresismo. Además, crear escuelas privadas formales no sólo era financieramente inviable, sino que alentaba conductas "elitistas" y cercenaban las vías de integración garantizadas por las leyes 1.420 de 1884 en Argentina, y 3.441 de 1909, en Uruguay. Entonces se resolvió, en cambio, fortalecer las instancias recreativas para continuar la transmisión ideológica (Visacovsky, 2015: 147-153).

Finalmente, la reconstrucción de los orígenes y el devenir de esta identidad judeo-progresista nos ha permitido observar que las tensiones entre la pertenencia étnica, los lineamientos del Partido Comunista y la aspiración colectiva de integración nacional experimentada por los inmigrantes fueron comunes en ambos países. Sus intentos de resolución, heredados por las nuevas generaciones, instalaron procesos contradictorios que, sin embargo, existian embrionariamente en su propia génesis.

\section{Bibliografía}

Altamirano, Carlos (2001), Peronismo y cultura de izquierda, Bueno Aires: Temas.

AMIA (1996), Comunidad Judia de Buenos Aires, 1894-1994, Buenos Aires: Milá.

Avni, Haim (1983), Argentina y la historia de la inmigración judia, 1810-1950, Jerusalén: Universitaria Magnes-Universidad Hebrea de Jerusalén.

Ben Dror, Graciela y Victor (2016), Sionismo radical socialista a orillas del Rio de la Plata: El Movimiento Mordechai Anielevich en Uruguay, 19541976, Yad Yairi: Rehovot.

Bilsky, Edgardo (1989), "Etnicidad y clase obrera: la presencia judía en el movimiento obrero argentino", Estudios Migratorios Latinoamericanos, año IV, $\mathrm{n}^{\circ} 11$, Buenos Aires, pp. 27-47.

Camarero, Hernán (2007), A la conquista de la clase obrera. Los comunistas y el mundo del trabajo en la Argentina, 1920-1935, Buenos Aires: Siglo XXI.

Carli, Sandra (2005), Niñez, pedagogía y politica, Buenos Aires: Miño y Dávila.

Crespo, Horacio (2010), "La Internacional Comunista", en Alexandra Pita Gonzalez (coord.), Intelectuales y antiimperialismo: entre la teoría y la práctica, México: Universidad de Colima, pp.15-47.

Devoto, Fernando (2004), Historia de la inmigración en la Argentina, Buenos Aires: Sudamericana.

Diaz, Hernán (coord.) (2019), Espionaje y revolución en el Río de la Plata. Los archivos secretos de una red diplomática de persecución al maximalismo (1918-1919), Buenos Aires: CEHTI-Imago Mundi.

Díaz, Javier (2016), "El anarquismo en el movimiento obrero judío de Bue- 
nos Aires (1905-1909)", Archivos de Historia del Movimiento Obrero y la Izquierda, $\mathrm{n}^{\circ} 8$.

Dujovne, Alejandro (2008), "Cartografia de las publicaciones periódicas judias de izquierda en Argentina, 1900-1953”, Revista del Museo de Antropología, Córdoba, año 1, pp. 121-138.

Feldman, Miguel (2001), Tiempos dificiles. Inmigrantes judios en el Uruguay 1933-1945, Montevideo: Universidad de la Republica.

Gilbert, Martin (1978), Los judios de la URSS. Su historia en mapas y fotografias, Jerusalén: La Semana Publicaciones.

Hobsbawm, Eric (2007), Historia del Siglo XX, Buenos Aires: Crítica.

Jmelnizky, Adrián y Ezequiel Erdei (2005), La población judia de Buenos Aires, Buenos Aires: JOINT-AMIA.

Katz, Pinie (1980), Páginas selectas, Buenos Aires: ICUF.

Kornecki, Vladimir (2005), Notas para la historia de ACIZ, Archivo ACIZ, Montevideo, traducida del ídish.

Laubstein, Israel (1997), Bund. Historia del movimiento obrero judio, Buenos Aires: Acervo Cultural.

Leibner, Gerardo (2011), Camaradas y compañeros. Una historia politica y social de los comunistas del Uruguay, Montevideo: Trilce.

Manzano,Valeria (2017), La era de la juventud en Argentina. Cultura, politica y sexualidad desde Perón hasta Videla, Buenos Aires: Fondo de Cultura Económica

Porzecanski, Teresa (1990), "Los inmigrantes judíos al Uruguay. Transculturación e ideologías de izquierda", en AA.VV., Ensayos sobre judaismo latinoamericano, Buenos Aires: Milá, pp. 84-103.

Raicher, Rosa Perla (2003), "El Comité Uruguayo Pro Palestina Hebrea (19441948). Su acción y cauces de pensamiento", Judaica Latinoamericana, Jerusalén: Amilat-Magnes-Universidad Hebrea, pp. 230-243.

Sak, Benito (2000), Toda una historia, Buenos Aires, mimeo.

Schonebohm, Dieter (1991), "Judíos de izquierda en Montevideo: La comunidad progresista", Hoy es Historia, año VIII, n 44, pp. 59-70.

Toker, Eliahu y Ana Weinstein (1999), Trayectoria de una idea, Nueva Sión: 50 años de periodismo judeo-argentino con compromiso, Buenos Aires: Fundación Mordejai Anilevich.

Visacovsky, Nerina (2015), Argentinos, judios y camaradas. Tras la utopia socialista, Buenos Aires: Biblos.

- (2017), "Entre odas a Sarmiento y la fe bolchevique: Aníbal Ponce y sus marcas en la cultura comunista", Claves. Revista de Historia, vol. $3, \mathrm{n}^{\circ}$ 5, Montevideo, pp. 38-70.

Wald, Pinie (1998), Pesadilla. Una novela de la Semana Trágica [1929], Buenos Aires, Ameghino.

Zadoff, Efraim (1994), Historia de la educación judia en Buenos Aires, 19351957, Buenos Aires: Milá. 